\title{
Processing and characterization of halloysite nanotubes filled polypropylene nanocomposites based on a masterbatch route: effect of halloysites treatment on structural and mechanical properties
}

\author{
K. Prashantha ${ }^{1,2 *}$, M. F. Lacrampe ${ }^{1,2}$, P. Krawczak $k^{1,2}$ \\ ${ }^{1}$ Univ. Lille Nord de France, F-59500 Lille, France \\ ${ }^{2}$ Ecole des Mines de Douai, Polymers and Composites Technology and Mechanical Engineering Department, \\ 941 rue Charles Bourseul, BP 10838, F-59508 Douai Cedex, France
}

Received 25 June 2010; accepted in revised form 4 November 2010

\begin{abstract}
Halloysites/polypropylene nanocomposites with different nanotubes contents were prepared by diluting a masterbatch containing $30 \mathrm{wt} . \%$ halloysites with polypropylene (PP). Unmodified (HNTs) and quaternary ammonium salt treated (QM-HNTs) halloysite nanotubes were used. Both degree of crystallinity and crystallization temperature increase upon addition of halloysites into PP, thus indicating a potential nucleation effect induced by the nanotubes. An homogeneous distribution and dispersion of nanotubes was observed throughout the PP matrix, with a slightly better dispersion in the case of modified QM-HNTs compared to unmodified HNTs. Mechanical tests in tension, bending and notched impact demonstrated that strength and modulus of the nanocomposites significantly increase with addition of halloysites without significant loss of ductility. An halloysite content of $6 \mathrm{wt} . \%$ appears as an optimum. Modified halloysites (QM-HNTs) lead to globally better performances due to strong interfacial interaction between the polymer matrix and the nanotubes.
\end{abstract}

Keywords: nanocomposites, polypropylene, halloysite nanotubes, masterbatch

\section{Introduction}

Polymer nanocomposites are new class of materials that are filled with nanofillers, and which usually exhibit exceptionally superior thermomechanical performance and physical properties at much lower filler loadings compared to conventional polymer composites [1-3]. Improvements in mechanical properties, such as stiffness and toughness, dimensional stability, electrical, barrier and thermal properties as well as fire retardant enhancements, with respect to the bulk polymer, are usually observed [1-3]. The interfacial interactions and the degree of dispersion of fillers in polymer matrix are key issues in determining the final performance of polymer nanocomposites [4-7].

Polypropylene (PP) is an important commercial plastic widely used to produce household goods and automotive parts due to its well-balanced physical and mechanical properties and easy processability at a relatively low cost. The application of PP in various industrial sectors can be further expanded once its mechanical performances have been highly upgraded. Therefore, PP has been a popular matrix used in association with all kinds of nanofillers such as carbon nanotubes (CNTs) [8-12], layered silicates (clays such as montmorillonite (MMT)

\footnotetext{
${ }^{*}$ Corresponding author, e-mail: kalappa.prashantha@mines-douai.fr
} (c) BME-PT 
etc.,) [13-15] and nanoparticles such as silica, graphite and calcium carbonate [16-19], even though the nanofiller dispersion is challenging in that case and often remains an issue.

Halloysite nanotubes (HNTs) have recently become the subject of research attention as a new type of additive for enhancing the mechanical, thermal and fire-retardant performance of polymers [20-32]. Halloysite is mainly composed of aluminosilicate and has a predominantly hollow tubular structure with the chemical composition $\mathrm{Al}_{2}(\mathrm{OH})_{4} \mathrm{Si}_{2} \mathrm{O}_{5}\left(2 \mathrm{H}_{2} \mathrm{O}\right)$. It is a weathering product of volcanic rocks of rhyolitic up to granitic composition and occurs in great deposits. Common halloysites can be found in form of fine, tubular structures with a length of 300 $1500 \mathrm{~nm}$, and with inner and outer diameters of 15$100 \mathrm{~nm}$ and 40-120 nm, respectively [33].

Even if the usage of a silica based, natural occurring nanotube as reinforcing material for polymers is still new, halloysite nanotubes are considered as the ideal materials for preparing polymer composites due to the fact that halloysites are rigid materials and that unique crystal structure of HNTs resembles that of carbon nanotubes (CNTs) in terms of aspect ratio. Compared with other nanoparticles such as fumed silica, montmorillonite, and carbon nanotubes, halloysite nanotubes are more easily dispersed in polymer matrix by shearing due to their rod-like geometry and limited intertubular contact area [33]. Chemically, HNTs are recognized for their relatively lower hydroxyl density on their outer surfaces compared with fumed silica and other layered silicates such as montmorillonite [21]. Therefore, the aggregation induced by the intertubular hydrogen bonding is susceptible to the shearing force. In fact, morphology study for many polymer/HNTs composites has shown single-tube dispersed halloysites in the matrix [34]. Halloysite nanotubes are readily obtainable, are much cheaper than other nanofillers such as carbon nanotubes and they are biocompatible [35]. In addition, only traces of heavy metals were detected, much lower than standards of the restriction of harmful substances of the European Union. Consequently it can be concluded that halloysite nanotubes (HNTs) are a type of 'green', unique and promising reinforcing material for thermoplastics [33].

Polypropylene does not have any polar groups that could interact with the halloysites. This usually results in poor level of dispersion of the halloysites in the PP matrix and a poor interfacial bonding between the filler surface and the PP matrix. This also limits the advantages of incorporation of the halloysites into the PP matrix. To overcome this problem, strategies such as compatabilization between fillers and PP have been reported, including the use of benzothiazole sulfide grafted polypropylene [31]. Pre-treatment of fillers with coupling agents is also well documented [28, 32]. Furthermore, surface modification of fillers also provides good wetting and bonding with polymers. Most common methods used for the production of polymer nanocomposites, are melt mixing, solution casting and in situ polymerization [36]. Among them, melt mixing is a most desirable method as it combines high shear with simplicity. Furthermore, it is free of solvents and contaminants and the required equipment for efficient manufacturing of large amounts of nanocomposites is already available in the plastics industry. In all the techniques mentioned above, a homogeneous dispersion and good interfacial adhesion are crucial for the successful preparation of nanocomposites [36-37]. Additionally, recent advancement in the usage of pre-elaborated masterbatches, usually containing 10-30 wt.\% nanofillers, facilitates both the processing and the formulation development and eliminates the dispersion and handling difficulties. A recent comprehensive study highlights the benefits and results obtained by dilution of commercially available carbon nanotube filled PP masterbatches [9]. However, whereas few reports are available in the literature, which examine the mechanical and structural properties of melt processed halloysite filled PP nanocomposites [28-32], no reports are available to our knowledge on detailed investigations on the properties of nanocomposites prepared via dilution of halloysite filled PP masterbatches. Moreover, distribution of masterbatch and subsequent dispersion of nanotubes in the polymer matrix after processing needs to be ascertained.

As a consequence, the present work aims at comparing the properties of as received halloysite nanotubes (HNTs)/PP and quaternary ammonium salt treated halloysite nanotubes (QM-HNTs)/PP nanocomposites produced with varying nanotube content by diluting a commercial available masterbatch in a twin screw extruder. The structure, morphology 
and mechanical properties (in tension, bending and impact) of the prepared nanocomposites were characterized.

\section{Experimental section}

\subsection{Materials}

The materials used in this study are two commercially available polypropylene based masterbatches (Pleximer ${ }^{\mathrm{TM}}$ PP grade, Natural Nano Inc, USA) containing $30 \mathrm{wt} . \%$ halloysite nanotubes: one unspecified quaternary ammonium salt treated halloysites (QM-HNTs) filled polypropylene and one unmodified halloysites (HNTs) filled polypropylene. Halloysites used in the masterbatch were mainly of tubular structure with a diameter smaller than $100 \mathrm{~nm}$ and lengths typically ranging from about 500 nanometers to over 1.2 microns with a density of $250 \mathrm{~kg} / \mathrm{m}^{3}$. The dilution matrix was made of homopolymer PP granules (FB 027 grade, Polychim, France) with a melt flow index of $12 \mathrm{~g} / 10 \mathrm{~min}$ at $190^{\circ} \mathrm{C}$.

\subsection{Preparation of nanocomposites}

Unmodified halloysite nanotubes (HNTs)/PP and quaternary ammonium salt treated halloysite nanotubes (QM-HNTs)/PP nanocomposites were produced by extrusion process by mixing homo PP granules with the commercial 'Pleximer' masterbatch containing $30 \mathrm{wt} . \%$ of halloysites. The dilution was carried out in a co-rotating twin screw extruder (Clextral BC 45, Clextral, France) at a screw speed of $50 \mathrm{rpm}$. The temperatures setting from the hopper to the die was $180 / 190 / 200 / 210^{\circ} \mathrm{C}$. During melt extrusion ventilation was kept on to remove trapped air in composites. After pelletizing, the nanocomposite granules were dried for 5 hours at $80^{\circ} \mathrm{C}$ before injection-molding. Dried pellets were injection-molded (KM80-160E injection molding machine, KraussMaffei, Germany) into standard test specimen for tensile, impact, flexural and dynamic mechanical analysis. The temperature profile setting ranged from 200 to $215^{\circ} \mathrm{C}$ and the mold temperature was kept at $25^{\circ} \mathrm{C}$. The holding pressure and screw rotation speed were 300 bar and $100 \mathrm{rpm}$, respectively with a throughput of $50 \mathrm{~cm}^{3} / \mathrm{s}$. The final nanocomposites bearing 2, 4, 6 and $8 \mathrm{wt} . \%$ fillers in the PP matrix were fabricated and as a reference, neat PP was also similarly extruded and injection-molded for mechanical and dynamic mechanical studies.

\subsection{Structural and morphological characterization}

Samples for scanning electron microscopy (SEM) were prepared by coating a thin layer of carbon onto the nanocomposite samples. Electron microscopy imaging of the nanocomposites was performed under high vacuum with a SEM instrument (S4300SE/N, Hitachi, Japan) operating at $5 \mathrm{kV}$.

For transmission electron microscopy (TEM), ultrathin sections were cut at ambient temperature with a microtome (Leica Reichert FCS, Leica Microsystems GmbH, Germany) and collected on a 300 mesh copper grid. Thickness of the ultrathin sections was $125 \mathrm{~nm}$. They were examined with a TEM (LEO 922) operated at $120 \mathrm{kV}$ and the micrographs were taken using an energy filter in zero loss mode for an optimal contrast of the nanotubes.

Differential scanning calorimetry (DSC 7, PerkinElmer, USA,) was performed under nitrogen atmosphere. The sample was heated from 35 to $200^{\circ} \mathrm{C}$ at a heating rate of $10^{\circ} \mathrm{C} / \mathrm{min}$, held at $210^{\circ} \mathrm{C}$ for $5 \mathrm{~min}$ to eliminate any previous thermal history, and then cooled to $35^{\circ} \mathrm{C}$ at a cooling rate of $10^{\circ} \mathrm{C} / \mathrm{min}$. The samples were kept at this temperature for another $5 \mathrm{~min}$ and heated again to $200^{\circ} \mathrm{C}$ at a heating rate of $10^{\circ} \mathrm{C} / \mathrm{min}$. On the basis of the recorded DSC thermograms, melting temperature $\left(T_{\mathrm{m}}\right)$, crystallization temperature $\left(T_{\mathrm{c}}\right)$, heat of fusion $\left(\Delta H_{\mathrm{m}}\right)$ and relative degree of crystallinity $\left(X_{\mathrm{c}}\right)$ were determined. $X_{\mathrm{c}}$ was calculated from the DSC crystallization curves with Equation (1):

$X_{\mathrm{c}}=\frac{\Delta H_{\mathrm{m}}}{\Delta H_{\mathrm{m}}^{\circ}\left(1-w_{\mathrm{t}}\right)}$

where $\Delta H_{\mathrm{m}}$ is the specific melting heat or heat of fusion, calculated by integrating the area under the crystallization peak, $\Delta H_{\mathrm{m}}^{\circ}$ is the theoretical specific melting heat of $100 \%$ crystalline isotactic $\mathrm{PP}$, which is taken as $209 \mathrm{~J} / \mathrm{g}$ [38], and $w_{\mathrm{t}}$ is the weight fraction of nanotubes.

\subsection{Dynamic mechanical analysis}

Dynamic mechanical properties were measured with a DMA (DMA +150, MetraviB, France) operating in the tensile mode at a frequency of $10 \mathrm{~Hz}$. 
The strain amplitude was $20 \mu \mathrm{m}$ and the static force was $1 \mathrm{~N}$ as per the reported procedure elsewhere [39]. Data were collected from $-50^{\circ} \mathrm{C}$ temperature to $120^{\circ} \mathrm{C}$ at a scanning rate of $3^{\circ} \mathrm{C} / \mathrm{min}$. DMA specimens were cut from injection-molded impact bar samples in the form of rectangular bars of nominal dimensions: $4( \pm 0.2) \mathrm{mm} \times 10( \pm 0.5) \mathrm{mm} \times 30 \mathrm{~mm}$. A minimum of 3 specimens of each composition were tested.

Dynamic mechanical analysis (DMA) is generally being used to study relaxation in polymers. An analysis of the storage modulus $\left(E^{\prime}\right)$, loss modulus $\left(E^{\prime \prime}\right)$, and loss factor $(\tan \delta)$ curves is very useful in evaluating the performance of samples under stress and temperature. It is well known that the $\tan \delta$ vs. temperature curve of PP exhibits three relaxations localized in the vicinity of $-80^{\circ} \mathrm{C}(\gamma), 10^{\circ} \mathrm{C}(\beta)$ and $100^{\circ} \mathrm{C}(\alpha)$ [40]. In the present work, the study was focused on the $\beta$-relaxation of PP that corresponds to the glass-rubber transition of the amorphous portions and the temperature of the maximum $\tan \delta$ peak is assigned to the glass transition temperature $\left(T_{\mathrm{g}}\right)$.

\subsection{Mechanical characterization}

Mechanical performance of all compounded materials was evaluated from injection-molded specimens. Tensile properties of the molded dogbone specimens were tested using a tensile machine (Model 1185, Instron, USA) at a crosshead rate of $20 \mathrm{~mm} / \mathrm{min}$ at $25^{\circ} \mathrm{C}(50 \%$ relative humidity $)$ according to the ISO 527 standard. The tensile strength, modulus and elongation at break of the PP and its nanocomposite samples could be directly obtained from the recorded stress-strain curves. Flexural properties of the nanocomposites were determined by three point bending tests as per ISO 178 standard at a thickness to span length ratio of 1:16 at a

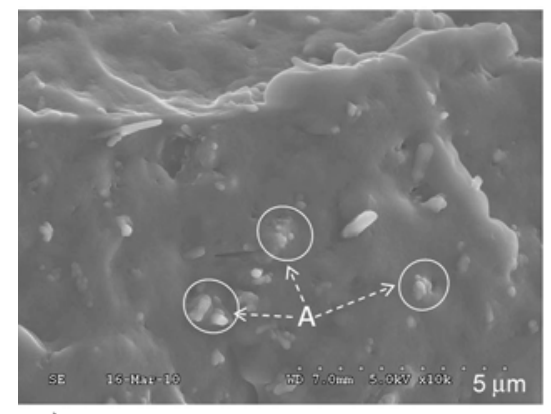

a) crosshead rate of $2 \mathrm{~mm} / \mathrm{min}$. Notched Charpy impact tests were carried out as per ISO 179-1 standard by using a pendulum impact machine (Model 5101, Zwick, Germany). The Charpy impact tests were performed on single-notched specimens at room temperature. All the reported values were calculated as averages over five specimens for each composition.

\section{Result and discussions}

\subsection{Structural and morphological characterization}

\subsubsection{Nanotube dispersion}

Scanning electron miscroscopy (SEM) and transmission electron microscopic (TEM) analysis were conducted on cryofractured nanocomposite samples in order to investigate the nanotube dispersion and interfacial features in nanocomposites. Figure 1a shows typical SEM micrograph of $6 \mathrm{wt} . \%$ HNTs filled nanocomposites. The nanotube distribution appears to be uniform across the specimen. Smaller agglomerates remain however, which are smeared out and well penetrated into the PP matrix (marked as ' $A$ ' in Figure 1a). This observation is further supported by TEM micrographs (Figure 2a), which confirm that melt-compounding grants fairly homogeneous dispersion of the HNTs within the polymer matrix with occasionally micron-sized aggregates scattered within a matrix of neat polypropylene (marked as ' $A$ ' in Figure 2a). Existence of agglomerates indicates insufficient interactions between HNTs and PP matrix. The microstructure of the nanocomposites is substantially changed after incorporation of $6 \mathrm{wt} . \%$ functionalized halloysites (PP/QM-HNTs) into PP matrix as shown in Figures $1 \mathrm{~b}$ and $2 \mathrm{~b}$. The aggregates previously observed for the nanocomposites containing non-modified halloysites (Figure 2a) are less or no more present

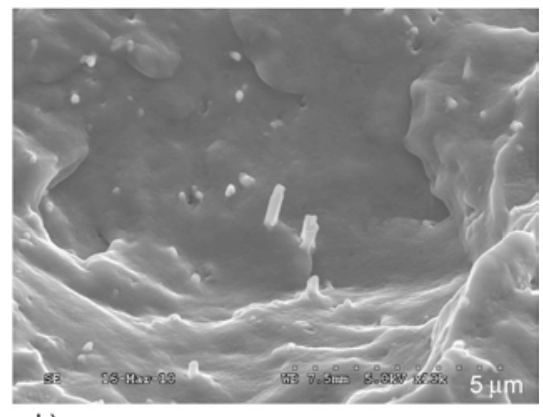

b)

Figure 1. Scanning electron microscopic images of 6 wt.\% nanotube filled PP/HNT (a) and PP/ QM-HNT (b) nanocomposites $-\mathrm{A}$ : aggregates of nanotubes 

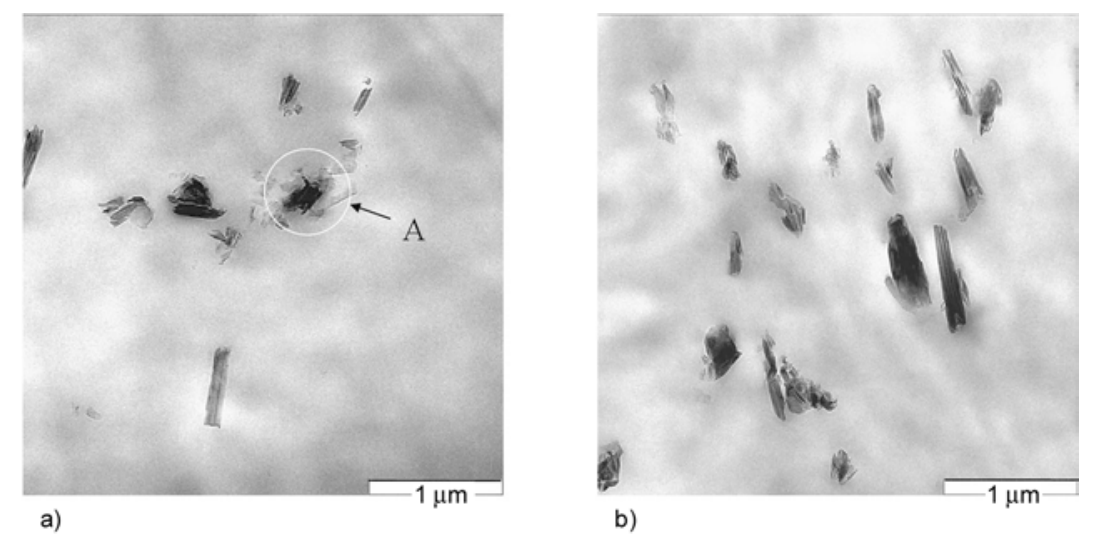

Figure 2. Transmission electron microscopic images of 6 wt.\% nanotube filled PP/HNT (a) and PP/QM-HNT (b) nanocomposites $-\mathrm{A}$ : aggregates of nanotubes

in modified halloysites filled nanocomposites. The improved dispersion of QM-HNT in PP may be explained by the fact that functional groups brought by quaternary ammonium salt present on the surface of halloysites decreases their surface free energy and hinders nanotube/nanotube interaction, thereby breaking up the aggregates during the extrusion process, and further improves the interface between fillers and the PP matrix. Besides, significant differences are also observed when considering the amount of individual nanotubes dispersed in the matrix, which is higher in the case of QM-HNTs. Overall microscopic analysis indicates that halloysite nanotubes are distributed and dispersed quite homogenously throughout the PP matrix with a good adhesion between nanotubes and PP, a slightly better dispersion being however noticed when QM-HNTs were used as filler.

\subsubsection{Crystallinity}

As the matrix crystallinity may have an influence on mechanical properties of nanocomposites, non-

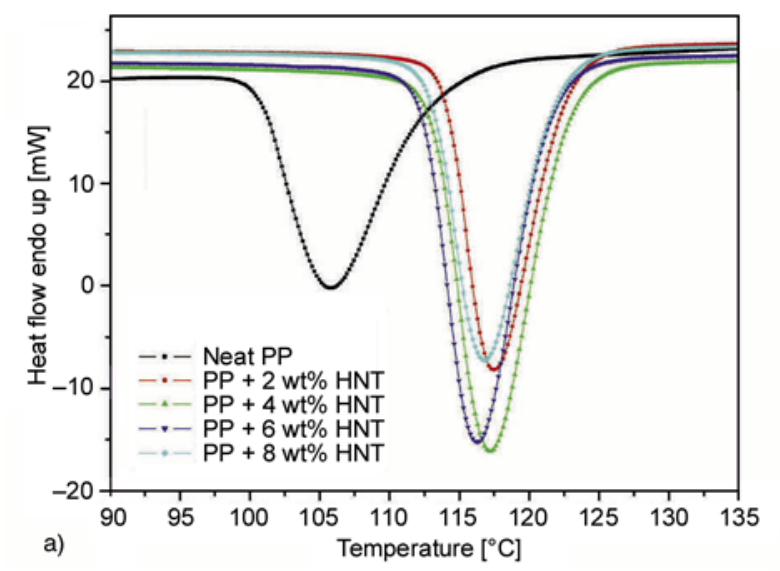

isothermal DSC experiment was also carried out. Figure 3 shows the crystallization curves obtained during cooling of the PP/HNTs (Figure 3a) and $\mathrm{PP} / \mathrm{QM}-\mathrm{HNTs}$ (Figure 3b) nanocomposites at different nanotube loadings. Relative degree of crystallinity $\left(X_{\mathrm{c}}\right)$ values of the various nanocomposites are reported in Table 1. The crystallization behaviour of polypropylene is affected by the addition of

Table 1. Crystallization temperature $\left(T_{\mathrm{c}}\right)$, melting temperature $\left(T_{\mathrm{m}}\right)$, heat of fusion $\left(\Delta H_{\mathrm{m}}\right)$ and degree of crystallinity $\left(X_{\mathrm{c}}\right)$ values for PP/HNT and PP/QM-HNT nanocomposites

\begin{tabular}{|l|c|c|c|c|}
\hline \multicolumn{1}{|c|}{ Material } & $\begin{array}{c}\mathbf{T}_{\mathbf{m}} \\
{\left[{ }^{\circ} \mathbf{C}\right]}\end{array}$ & $\begin{array}{c}\mathbf{T}_{\mathbf{c}} \\
{\left[{ }^{\circ} \mathbf{C}\right]}\end{array}$ & $\begin{array}{c}\Delta \mathbf{H}_{\mathbf{m}} \\
{[\mathbf{J} / \mathbf{g}]}\end{array}$ & $\begin{array}{c}\mathbf{X}_{\mathbf{c}} \\
{[\% \mathbf{}]}\end{array}$ \\
\hline PP & 163.2 & 105.7 & 85.90 & 41.1 \\
\hline PP + 2 wt.\% HNT & 163.5 & 117.6 & 90.07 & 44.0 \\
\hline PP + 4 wt.\% HNT & 163.4 & 117.2 & 92.10 & 45.9 \\
\hline PP + 6 wt.\% HNT & 163.3 & 116.3 & 90.41 & 46.0 \\
\hline PP + 8 wt.\% HNT & 163.4 & 116.7 & 88.72 & 45.2 \\
\hline PP + 2 wt.\% QM-HNT & 163.3 & 116.6 & 93.25 & 45.5 \\
\hline PP + 4 wt.\% QM-HNT & 163.7 & 116.5 & 94.74 & 47.2 \\
\hline PP + 6 wt.\% QM-HNT & 163.2 & 117.5 & 94.85 & 48.3 \\
\hline PP + 8 wt.\% QM-HNT & 163.3 & 117.4 & 90.98 & 47.3 \\
\hline
\end{tabular}

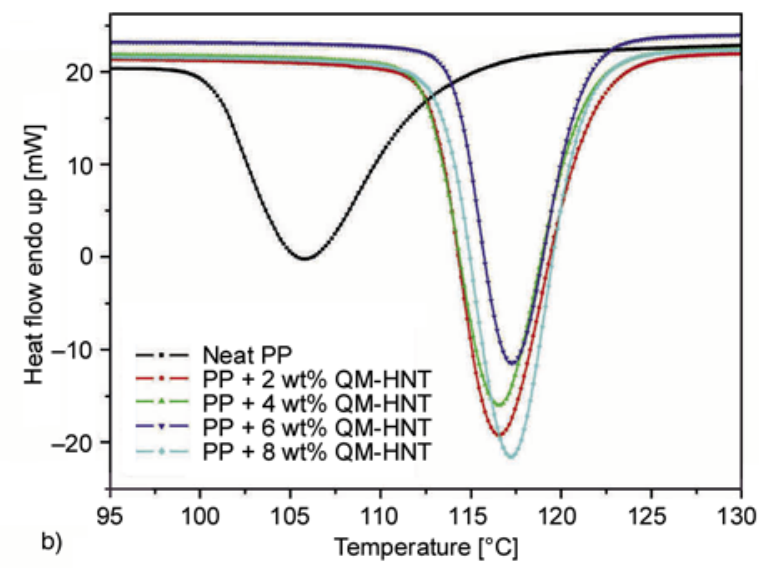

Figure 3. DSC cooling thermograms of the PP/HNT (a) and PP/QM-HNT (b) nanocomposites at different nanotube loadings 
halloysite nanotube. The crystallinity $\left(X_{\mathrm{c}}\right)$ of $\mathrm{PP} /$ HNTs increased from $41.1 \%$ up to $45 \% \pm 1 \%$ and $46.6 \% \pm 1.6 \%$ after adding HNTs and QM-HNTs, respectively. The increase is maximum and reaches in relative values, compared to neat $\mathrm{PP},+12 \%$ (respectively $+17.6 \%$ ) at an halloysite content of 6 wt.\%. These results further indicate that halloysites may act as nucleation sites for the crystallization of polypropylene and accelerate the crystallization process in PP matrix by increasing the growth rate of spherulite [41]. The spherulite size may also reduce upon addition of HNTs. Significantly higher crystallinity and lower spherulite size may partly contribute to the enhancement of mechanical properties (increase in modulus and strength) of the nanocomposites (see section 3.4). However, decrease in percentage crystallinity was observed for $8 \mathrm{wt} . \%$ halloysite filled nanocomposites. This may be ascribed to the fact that, dispersions of halloysites become poor at relatively higher halloysite content and this hinders the increase of crystallinity in the nanocomposites.

\subsection{Thermal properties}

Crystallization temperature $\left(T_{\mathrm{c}}\right)$ and melting temperature $\left(T_{\mathrm{m}}\right)$ values of the various nanocomposites are also reported in Table 1. Compared to neat PP, no significant change is observed in the melting point $T_{\mathrm{m}}$ of polypropylene nanocomposites, which is logical as halloysites are mineral fillers. On the contrary, the addition of halloysite nanotubes to the polypropylene matrix induces an increase in crystallization temperature $T_{\mathrm{c}}$ by more than $10^{\circ} \mathrm{C}$. The crystallization peak appears at $105.7^{\circ} \mathrm{C}$ for the PP matrix and shifts to higher temperatures as the

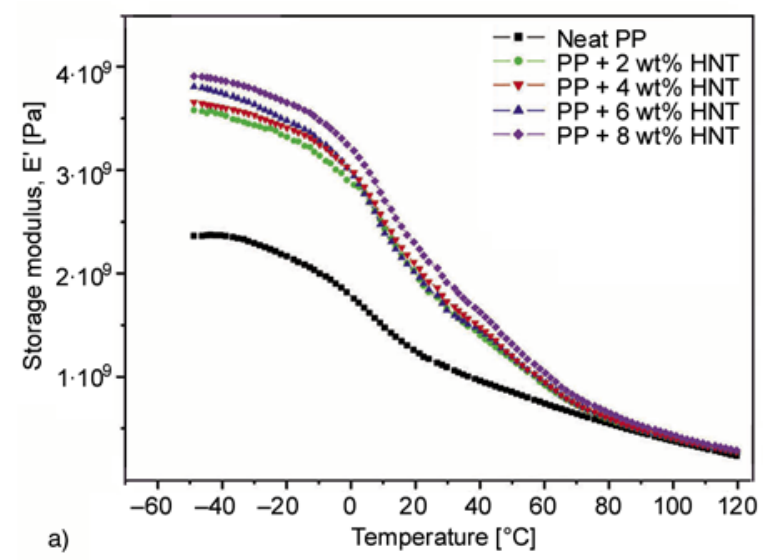

amount of nanotube increases, confirming that halloysites nanotubes act as nucleating agents. Similar behavior has been reported previously in literature for other polypropylene based nanocomposites (with CNTs or MMT) [42-43]. There is no clear or significant dependence of $T_{\mathrm{c}}$ on halloysite nanotube amount. The crystallization peak also appears to be narrower in the case of all nanocomposites.

\subsection{Dynamic mechanical properties.}

The dynamic mechanical properties of PP and its nanocomposites, with unmodified and modified halloysite nanotubes, are represented in Figures 4 and 5. Figure 4 shows the dynamic storage modulus as a function of temperature for PP and its nanocomposites. The results clearly indicate that, storage modulus $\left(E^{\prime}\right)$ of all nanocomposites (modified and unmodified) is higher than that of neat PP. Storage modulus of PP increases with increasing halloysites content, which is due to the reinforcement effect and restrictions in the chain mobility. This means that the incorporation of halloysites into PP matrix remarkably enhances stiffness and load bearing capability of the material. Furthermore, increase in storage modulus for the nanocomposites bearing modified halloysites i.e. PP/QM-HNTs (Figure 4b) is much higher than that of nanocomposites bearing as received halloysites i.e. PP/HNTs (Figure 4a). The rate of increase of storage modulus with increase in QM-HNTs content in the matrix is more pronounced than that of PP/HNTs references. This illustrates the more efficient stiffening/reinforcement effect of QM-HNTs. The increase in the modulus confirms the formation of highly dispersed nanocomposites with improved interfacial interactions

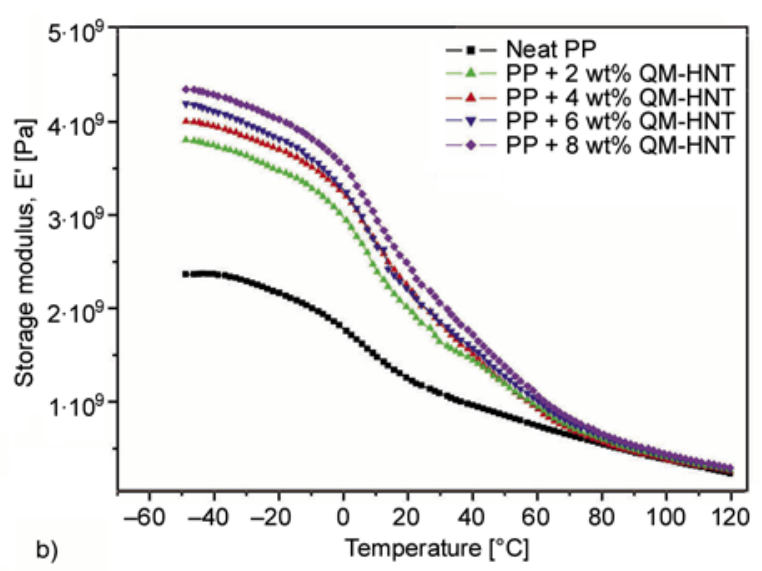

Figure 4. Storage modulus $\left(E^{\prime}\right)$ with temperature sweep as a function of nanotube content for PP/HNT (a) and PP/QM-HNT (b) nanocomposites 

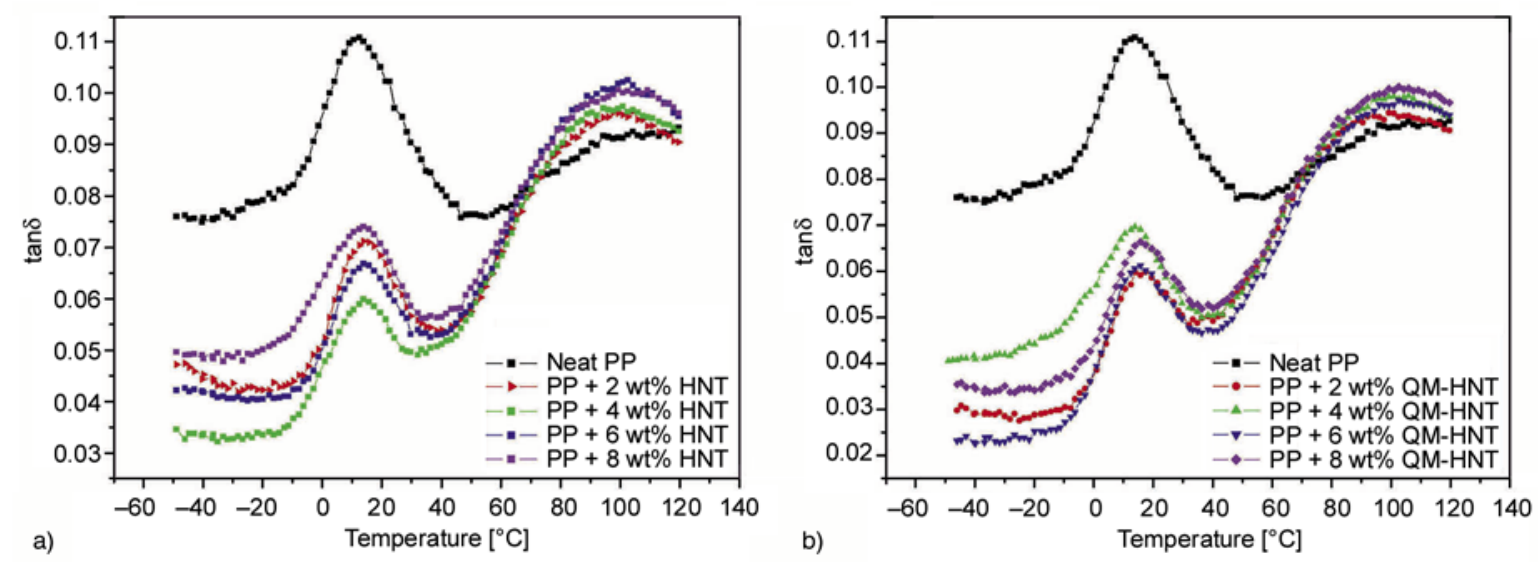

Figure 5. Tan $\delta$ with temperature sweep as a function of nanotube content for PP/HNT (a) and PP/QM-HNT (b) nanocomposites

Table 2. Glass transition temperature $\left(T_{\mathrm{g}}\right)$ and $\tan \delta$ of $\mathrm{PP} /$ HNTs and PP/QM-HNTs nanocomposites

\begin{tabular}{|l|c|c|}
\hline \multicolumn{1}{|c|}{ Material } & $\left.\mathbf{T}_{\mathbf{g}}{ }^{\circ}{ }^{\circ} \mathbf{C}\right]$ & $\tan \boldsymbol{\delta}$ at peak \\
\hline $\mathrm{PP}$ & 12.5 & 0.107 \\
\hline $\mathrm{PP}+2$ wt.\% HNT & 13.9 & 0.076 \\
\hline $\mathrm{PP}+4$ wt.\% HNT & 13.8 & 0.060 \\
\hline $\mathrm{PP}+6$ wt.\% HNT & 12.5 & 0.066 \\
\hline $\mathrm{PP}+8$ wt.\% HNT & 13.8 & 0.067 \\
\hline $\mathrm{PP}+2$ wt.\% QM-HNT & 15.6 & 0.060 \\
\hline $\mathrm{PP}+4$ wt.\% QM-HNT & 15.7 & 0.069 \\
\hline $\mathrm{PP}+6$ wt.\% QM-HNT & 13.8 & 0.061 \\
\hline $\mathrm{PP}+8$ wt.\% QM-HNT & 13.9 & 0.066 \\
\hline
\end{tabular}

between nanotubes and matrix as evidenced by the microscopy analysis.

Figure 5 illustrates the effect of halloysite nanotubes on the loss factor $(\tan \delta)$ for PP nanocomposites. The glass transition temperatures $T_{\mathrm{g}}$ of prepared nanocomposites, derived from $\log \tan \delta^{-} T$ curves (temperature at peak $\tan \delta$ ), are slightly higher than that of neat PP in general (except 6 wt.\% HNT nanocomposites, which showed a $T_{\mathrm{g}}$ value similar to PP) (Table 2). All QM-HNTs filled nanocompos-

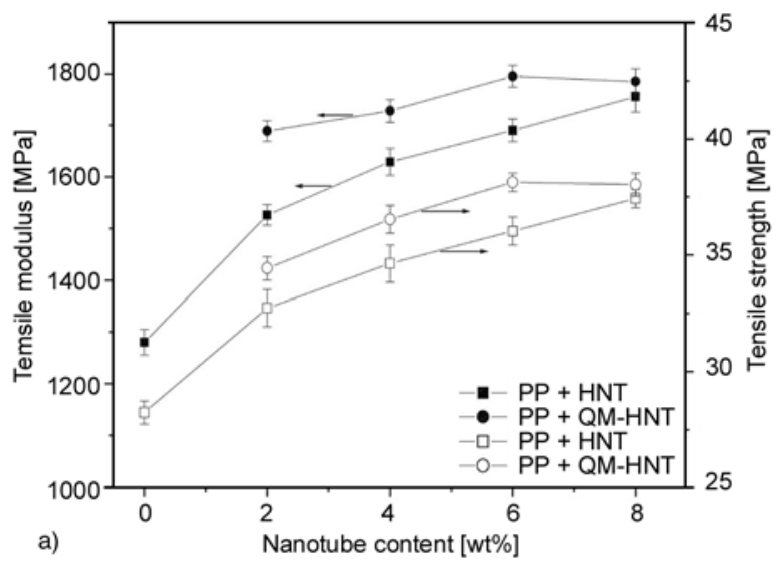

ites showed $T_{\mathrm{g}}$ values, higher than neat PP and PP/ HNTs nanocomposites (Table 2). It is well known that the $T_{\mathrm{g}}$ of a polymer depends on the mobility of the chain segment of the macromolecules in the polymer matrix. If the molecular chain is restricted, motion or relaxation of the chain segment becomes difficult at the original glass transition temperature and becomes easy at higher temperature [44]. Therefore, the increase in $T_{\mathrm{g}}$ values may be related to the degree of nanotubes homogeneous dispersion in the polymer matrix and the interactions between the filler and polymer, which is consistent with the reported literature on PP/clay [44].

\subsection{Mechanical properties}

\subsubsection{Tensile properties}

The effect of both untreated and treated halloysite nanotubes on the tensile properties of PP is depicted in Figure 6. It is evident that with the incorporation of HNTs, tensile strength (determined as the maximum of the stress-strain curve, i.e. the yield stress)

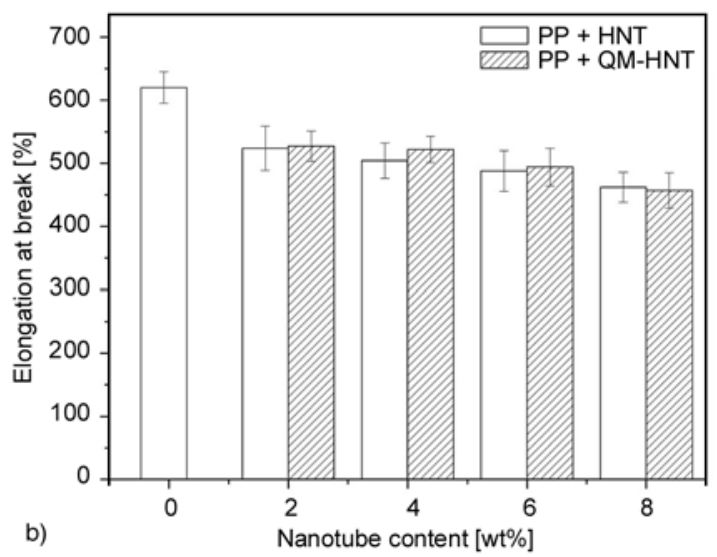

Figure 6. Tensile properties (a) and elongation at break (b) of PP/HNT and PP/QM-HNT nanocomposites 


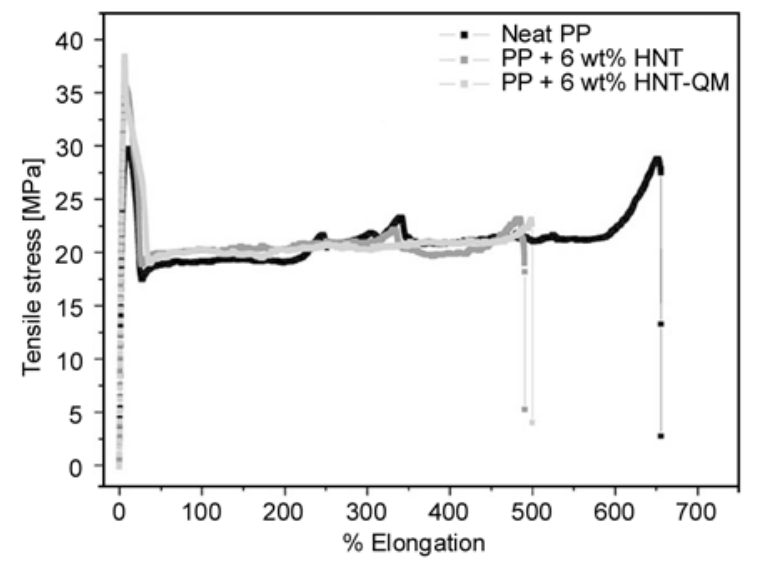

Figure 7. The typical tensile stress-starin curves of PP/HNT and PP/QM-HNT nanocomposites

and tensile modulus (Figure 6a) of PP gradullay increase with increase in nanotube content with a slight reduction ( -15 to $-25 \%)$ in the elongation at break (Figure 6b), indicating the reinforcing benefits of halloysites within PP matrix. The percentage increase ranges from 19 to $37 \%$ for Young's modulus and from 15 to $32.5 \%$ for yield stress, depending on HNT concentration. In case of modified halloysites (QM-HNTs), this increase ranges from 32 to $40 \%$ for Young's modulus and from 22 to $35 \%$ for yield stress, a plateau being achieved at a nanotubes content of $6 \mathrm{wt} . \%$. The typical tensile stressstrain curves of nanocomposite samples at optimized halloysite content i.e. at $6 \mathrm{wt} . \%$ halloysites is shown in Figure 7.

Overall results indicate that the improvement range of the mechanical properties, compared to neat PP, is larger for PP/QM-HNTs than for PP/HNTs nanocomposites. These results suggest that the utilization of surface modified nanotubes is essential to achieve higher strength and stiffness at very low nanofiller concentrations. Increase in tensile strength and modulus in PP/QM-HNTs nanocomposites without much loss in ductility (i.e. elongation at break) may be explained by better dispersion of the nanotubes within the matrix as well as improved inter-tubular and interfacial interactions between the QM-HNTs and PP matrix. Similar trends have been reported by Pasbakhsh et al. for ethylene propylene diene monomer/modified halloysite nanocomposites [45].

\subsubsection{Bending properties}

To further assess the reinforcing efficiency of halloysites, flexural properties of the modified and

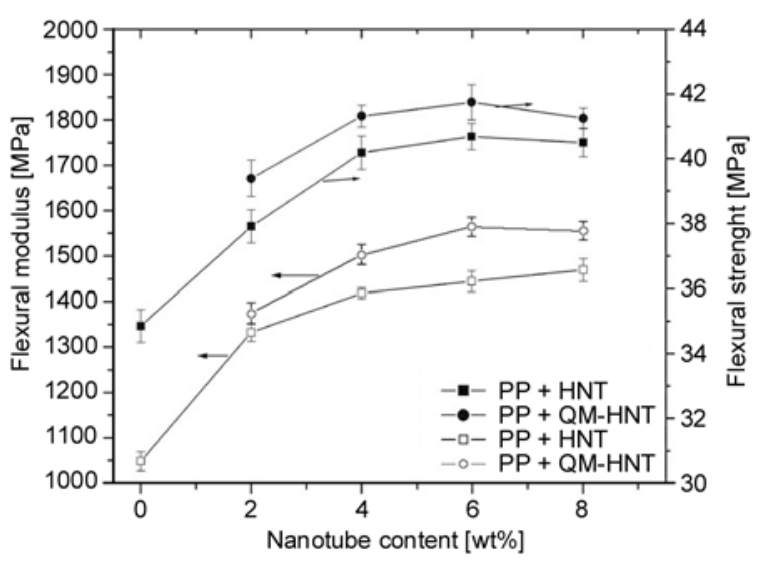

Figure 8. Flexural properties of $\mathrm{PP} / \mathrm{HNT}$ and $\mathrm{PP} / \mathrm{QM}-\mathrm{HNT}$ nanocomposites.

unmodified halloysite nanotubes filled PP nanocomposites were also investigated (Figure 8 ). It appears that addition of halloysite nanotubes leads to an improvement in the flexural modulus and strength of PP. As shown in Figure 7, the maximum percentage increase is about $43 \%$ for bending modulus and $16 \%$ for bending strength in case of as received halloysites (HNTs), whereas it reaches again slightly higher values, about $49 \%$ for bending modulus and $20 \%$ for bending strength, in case of modified halloysites. A nanotube content of $6 \mathrm{wt} . \%$ appear to be an optimal value as flexural properties tend to reach a plateau above this value (and sometimes even decrease). Decrease in flexural properties at higher loadings (i.e. $8 \mathrm{wt} . \%$ QM-HNTs) is due to the fact that overloadings of halloysites leads to agglomeration of nanotubes, such micron-sized aggregates acting as weak points and failure initiation sites. Similar observations have been reported by Liu et al. [46], for halloysites filled epoxy nanocomposites.

\subsubsection{Impact properties}

The effect of halloysite loadings on the notched Charpy impact strength of PP/HNTs and PP/QMHNTs nanocomposite is shown in Figure 9. It can be seen that the impact strength of all nanocomposites irrespective of filler type increases with increase in nanotube content. The maximum increase, reaching 70 , was here again found at 6 wt.\% nanotube loadings. Further addition of halloysite nanotubes reduces the impact strength of nanocomposites. The decrease in impact strength at higher halloysite loadings (i.e. at $8 \mathrm{wt} . \%$ ) is due to the fact that the increase in nanotubes content leads to the formation 


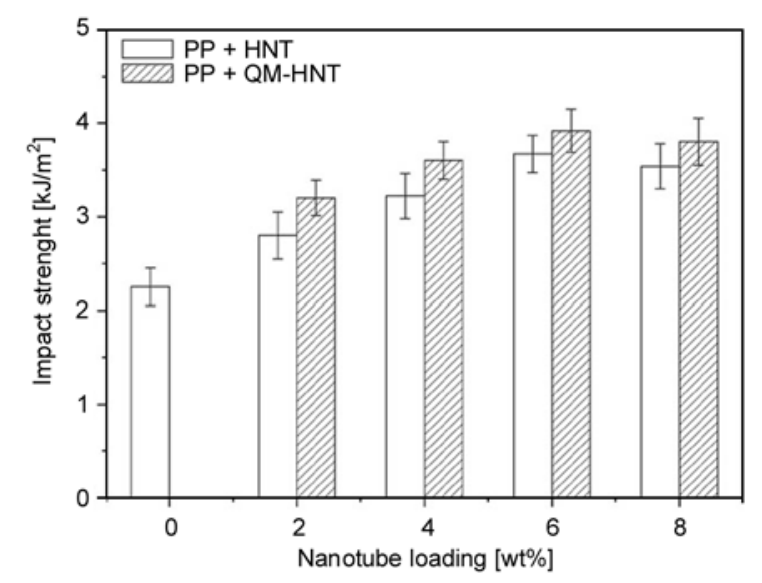

Figure 9. Notched Charpy properties of PP/HNT and PP/QM-HNT nanocomposites

of aggregates, which acts as a stress concentrator in the sample, which intiates a brittle failure. Increase in impact strength for the PP/HNTs is due to the intrinsic toughening properties of the halloysites [23]. Impact strength of notched PP/QM-HNTs samples showed slightly better resistance than that of PP/HNT samples (Figure 9). This is attributed to the fact that modifier on the surface of halloysites promotes the efficient interfacial shear stress transfer between PP and halloysites. A better interfacial interaction could lead to improvement of impact strength with high absorption energy during impact deformation. Figure 10 illustrates the fractured surface of high energy consumed i.e. 6 wt. $\%$ filled $\mathrm{PP} / \mathrm{HNT}$ and PP/QM-HNTs nanocomposites. Nanotube pullout (marked 'A') and nanotube breakage (marked 'B') may be clearly seen for PP/HNTs nanocomposites (Figure 10a). In case of PP/QMHNT nanocomposites, in addition to nanotube pullout and breakage, nanotube bridging (marked ' $\mathrm{C}$ ') seems to be another possible toughening factor (Figure 10b). Also, higher impact energy for PP/QMHNTs nanocomposites is due to the better disper-

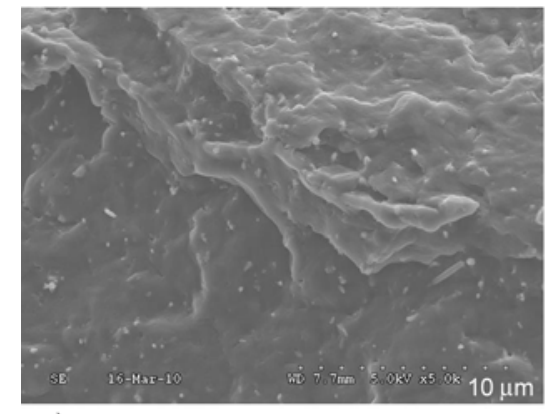

a) sion and distribution of modified nanotubes in the matrix. In addition, large aspect ratio of nanotubes would cause complex matrix-filler interaction during nanotube bridging, breaking and pullout, which probably promotes the local plastic deformation of matrix [47].

\subsubsection{Comparison of halloysites reinforcement potential with other nanofillers}

It is also worth comparing the reinforcement potential of halloysites with other nanofillers, such as carbon nanotubes (e.g. MWNT [9]) or layered silicates (e.g. MMT clay [48, 49]) melt-compounded with PP using similar processing conditions. Table 3 shows the percentage variations of mechanical properties of PP nanocomposites containing similar amounts ( 2 or 4 wt.\%) of MWNTs, MMT and QMHNTs compared to neat PP matrix. The order of magnitude of the increase in moduli and strengths observed in tension, bending and notched Charpy impact is globally the same for the three nanofillers. However, whereas the elongation at break decreases drastically by $-75 \%$ for carbon nanotubes and by about $-80 \%$ for montmorillonite, it remains almost unaltered for halloysites (property loss less than $20 \%$ ). It is also worth noting that, compared to montmorillonite, halloysite nanotubes yield a significantly higher increase in impact resistance, the percentage variation being even higher when the nanofiller weight content tends to reach its optimum value. Table 3 thus compares the percentage variations of mechanical properties of PP nanocomposites containing different nanofillers at their optimum loadings, which is $2 \mathrm{wt} . \%$ for MWNT/PP, 4 wt.\% for MMT/PP, 6 wt. \% for QM-HNTs/PP. Halloysites clearly provide the best reinforcement potential compared with carbon nanotubes and montmorillonite. Whereas the same (if not higher)

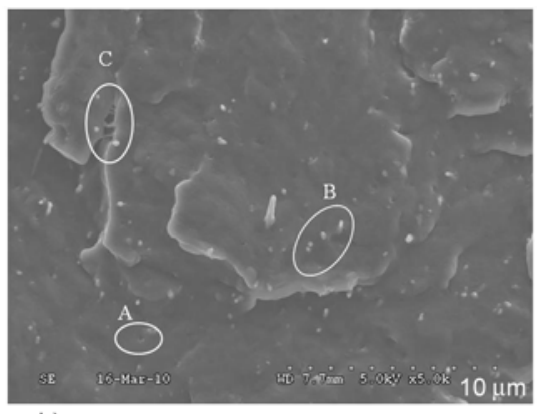

b)

Figure 10. Fracture surface of notched Charpy impact tested samples for 6 wt.\% nanotube filled PP/HNT (a) and PP/QMHNT (b) nanocomposites - A: nanotube pullout ; B: nanotube breakage ; C: nanotube bridging 
Table 3. Percentage variations of mechanical properties of nanocomposites containing MWNT, MMT and HNTs nanofillers (compared with neat PP matrix)

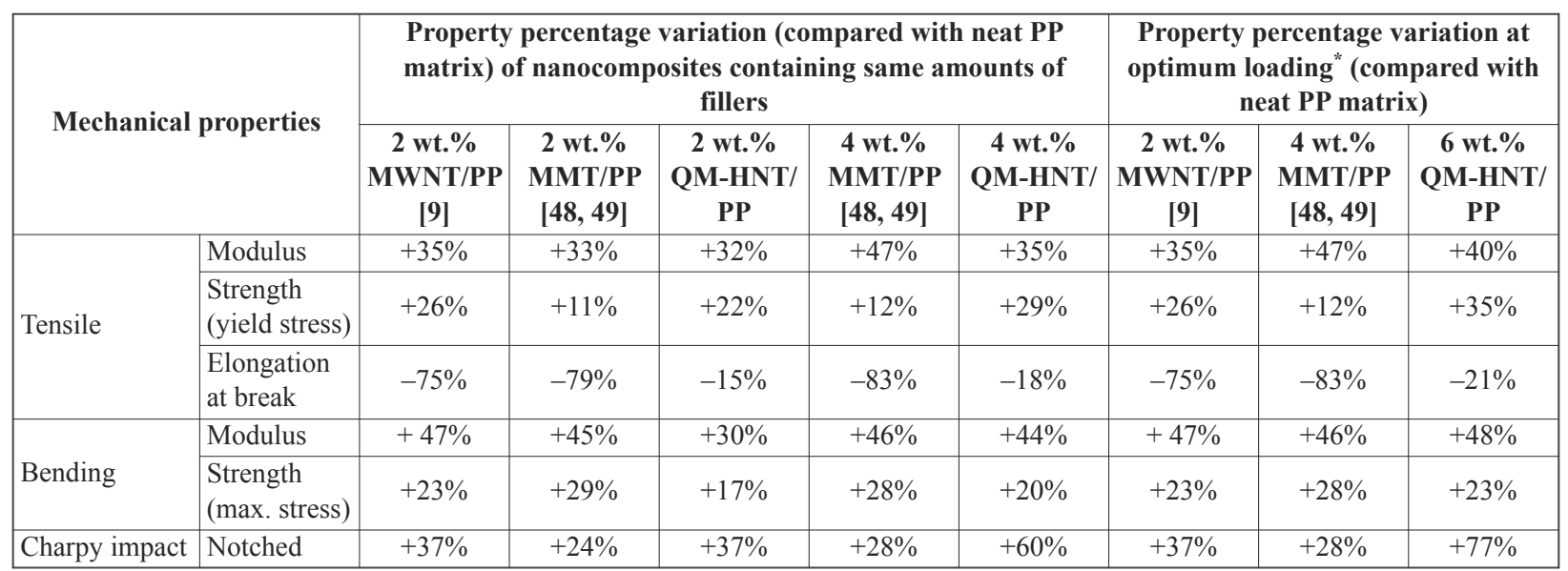

* Optimum loading is 2 wt.\% for MWNT/PP, 4 wt. \% for MMT/PP, 6 wt. $\%$ for QM-HNT/PP

percentage increases of moduli and strength in tension and bending are noticed for the three nanofillers, halloysites are characterized by almost no reduction $(-21 \%$ only) of the elongation at break and a huge $(+77 \%)$ percentage increase in impact strength.

These results may be explained by the fact that carbon nanotubes have a tendency to form agglomerates in the composites. Similarly montmorillonite clay suffers from a lack of formation of an exfoliated clay network structure and a mere dispersion of tactoids in the PP matrix. These tactoids and agglomerates usually act as crack initiation sites leading to sudden failure of the material. Comparatively, halloysite nanotubes are less prone to form agglomerates. Additionally, halloysites are discrete nanofillers with no or little surface charge and therefore, halloysite nanotubes may not require the intercalation and exfoliation process, as required by nanoclay fillers (33). These results indicate an obvious advantage in using halloysite over clays or carbon nanotubes, as filler for polymer composites.

\section{Conclusions}

Natural nanotubes (halloysites) filled polypropylene nanocomposites were successfully prepared by an industrially benign masterbatch dilution technique using high shear extrusion process followed by injection molding.

The influence of addition of both unmodified halloysite nanotubes (HNTs) and quaternary ammo- nium salt modified halloysite nanotubes (QM-HNTs) on structural and mechanical and properties of polypropylene (PP) nanocomposites was investigated for different halloysites weight contents. Differential scanning calorimetry showed that both degree of crystallinity and crystallization temperature increase upon addition of halloysites into PP, thus indicating a potential nucleation effect induced by the nanotubes. Scanning and transmission electron microscopy highlighted an homogeneous distribution and dispersion of nanotubes throughout the PP matrix, with a slightly better dispersion in the case of QM-HNTs compared to HNTs. Dynamic mechanical analysis evidenced a slight increase in glass transition temperature as well as an improvement in storage modulus with the incorporation of halloysites, more important for QM-HNTs than for HNTs. Mechanical tests demonstrated that strength and modulus of the nanocomposites significantly increase with addition of halloysites without significant loss of ductility. A halloysite content of $6 \mathrm{wt} . \%$ appears to be optimum as mechanical properties in tension, bending and impact tend to reach a plateau or even to decrease above this value. Quarternary ammonium salt modified halloysites (QM-HNTs) lead to globally better performances, which has been ascribed to the synergistic effects of surface modified nanotubes and well dispersed nanotubes on a nano-scale in the PP matrix, and in a lesser extent to the increase in the crystallinity. 


\section{Acknowledgements}

The authors are grateful to the Nord-Pas-de-Calais Region and to the European Community (FEDER) for having partly funded the DMA equipment in the frame of the International Campus on Safety and Intermodality in Transportation (CISIT).

\section{References}

[1] Alexandre M., Dubois P.: Polymer-layered silicate nanocomposites: Preparation, properties and uses of a new class of materials. Material Science and Engineering: Review, 28, 1-63 (2000). DOI: 10.1016/S0927-796X(00)00012-7

[2] Prashantha K., Soulestin J., Lacrampe M. F., Krawczak P.: Present status and key challenges of carbon nanotubes reinforced polyolefins: A review on nanocomposites manufacturing and performance issues. Polymers and Polymer Composites, 17, 205-245 (2009).

[3] Shi Z., Gao X., Song D., Zhou Y., Yan D.: Preparation of poly( $\varepsilon$-caprolactone) grafted titanate nanotubes. Polymer, 48, 7516-7522 (2007).

DOI: $10.1016 /$ j.polymer.2007.10.037

[4] Laine R. M., Choi J. W., Lee I.: Organic-inorganic nanocomposites with completely defined interfacial interactions. Advanced Materials, 13, 800-803 (2001). DOI: 10.1002/1521-4095(200106)13:11<800::AIDADMA800>3.0.CO;2-G

[5] Rong M. Z., Zhang M. Q., Pan S. L., Lehmann B., Friedrich K.: Analysis of the interfacial interactions in polypropylene/silica nanocomposites. Polymer International, 53, 176-183 (2004).

DOI: $10.1002 /$ pi.1307

[6] Kelnar I., Khunova V., Kotek J., Kaprálková L.: Effect of clay treatment on structure and mechanical behavior of elastomer-containing polyamide 6 nanocomposite. Polymer, 48, 5332-5339 (2007).

DOI: $10.1016 /$ j.polymer.2007.06.062

[7] Lim J. S., Noda I., Im S. S.: Effect of hydrogen bonding on the crystallization behavior of poly(3-hydroxybutyrate-co-3-hydroxyhexanoate)/silica hybrid composites. Polymer, 48, 2745-2754 (2007).

DOI: 10.1016/j.polymer.2007.03.034

[8] Bao S. P., Tjong S. C.: Mechanical behaviors of polypropylene/carbon nanotube nanocomposites: The effects of loading rate and temperature. Material Science and Engineering: A, 485, 508-516 (2008).

DOI: $10.1016 /$ j.msea.2007.08.050

[9] Prashantha K., Soulestin J., Lacrampe M. F., Krawczak P., Dupin G., Claes M.: Masterbatch-based multiwalled carbon nanotube filled polypropylene nanocomposites: Assessment of rheological and mechanical properties. Composites Science and Technology, 69, 1756-1763 (2009).

DOI: $10.1016 /$ j.compscitech.2008.10.005
[10] Prashantha K., Soulestin J., Lacrampe M. F., Krawczak P., Dupin G., Claes M.: Taguchi analysis of shrinkage and warpage of injection-moulded polypropylene/multiwall carbon nanotubes nanocomposites. Express Polymer Letters, 3, 630-638 (2009). DOI: $10.3144 /$ expresspolymlett.2009.79

[11] Zhang H., Zhang Z.: Impact behaviour of polypropylene filled with multi-walled carbon nanotubes. European Polymer Journal, 43, 3197-3207 (2007).

DOI: $10.1016 /$ j.eurpolymj.2007.05.010

[12] López Manchado M. A., Valentini L., Biagiotti J., Kenny J. M.: Thermal and mechanical properties of single-walled carbon nanotubes-polypropylene composites prepared by melt processing. Carbon, 43, 1499-1505 (2005).

DOI: $10.1016 /$ j.carbon.2005.01.031

[13] Hári J., Dominkovics Z., Fekete E., Pukánszky B.: Kinetics of structure formation in PP/layered silicate nanocomposites. Express Polymer Letters, 3, 692-702 (2009).

DOI: $10.3144 /$ expresspolymlett.2009.87

[14] Chinellato A. C., Vidotti S. E., Hu G-H., Pessan L. A.: Compatibilizing effect of acrylic acid modified polypropylene on the morphology and permeability properties of polypropylene/organoclay nanocomposites. Composites Science and Technology, 70, 458465 (2010).

DOI: 10.1016/j.compscitech.2009.11.020

[15] Betega de Paiva L., Morales A. R., Ribeiro Guimarães T.: Structural and optical properties of polypropylenemontmorillonite nanocomposites. Materials Science and Engineering: A, 447, 261-265 (2007).

DOI: $10.1016 /$ j.msea.2006.10.066

[16] Papageorgiou G. Z., Achilias D. S., Bikiaris D. N., Karayannidis G. P.: Crystallization kinetics and nucleation activity of filler in polypropylene/surface-treated $\mathrm{SiO}_{2}$ nanocomposites. Thermochimica Acta, 427, 117-128 (2005).

DOI: $10.1016 /$ j.tca.2004.09.001

[17] Mubarak Y. A., Abbadi F. O., Tobgy A. H.: Effect of iron oxide nanoparticles on the morphological properties of isotactic polypropylene. Journal of Applied Polymer Science, 115, 3423-3433 (2010).

DOI: $10.1002 / a p p .31374$

[18] Causin V., Marega C., Marigo A., Ferrara G., Ferraro A.: Morphological and structural characterization of polypropylene/conductive graphite nanocomposites. European Polymer Journal, 42, 3153-3161 (2006). DOI: 10.1016/j.eurpolymj.2006.08.017

[19] Yang K., Yang Q., Li G., Sun Y., Feng D.: Morphology and mechanical properties of polypropylene/calcium carbonate nanocomposites. Materials Letters, 60, 805809 (2006).

DOI: $\underline{10.1016 / j . m a t l e t .2005 .10 .020 ~}$ 
[20] Guo B., Lei Y., Chen F., Liu X., Du M., Jia D.: Styrene-butadiene rubber/halloysite nanotubes nanocomposites modified by methacrylic acid. Applied Surface Science, 255, 2715-2722 (2008).

DOI: $10.1016 / \mathrm{j}$. apsusc.2008.07.188

[21] Liu M., Guo B., Zou Q., Du M., Jia D.: Interactions between halloysite nanotubes and 2,5-bis(2-benzoxazolyl) thiophene and their effects on reinforcement of polypropylene/halloysite nanocomposites. Nanotechnology, 19, 205709 (2008).

DOI: $10.1088 / 0957-4484 / 19 / 20 / 205709$

[22] Ye Y., Chen H., Wu J., Ye L.: High impact strength epoxy nanocomposites with natural nanotubes. Polymer, 48, 6426-6433 (2007).

DOI: $10.1016 /$ j.polymer.2007.08.035

[23] Deng S., Zhang J., Ye L., Wu J.: Toughening epoxies with halloysite nanotubes. Polymer, 49, 5119-5127 (2008). DOI: 10.1016/j.polymer.2008.09.027

[24] Marney D. C. O., Russell L. J., Wu D. Y., Nguyen T., Cramm D., Rigopoulos N., Wright N., Greaves M.: The suitability of halloysite nanotubes as a fire retardant for nylon 6. Polymer Degradation and Stability, 93, 1971-1978 (2008).

DOI: $10.1016 /$ j.polymdegradstab.2008.06.018

[25] Ismail H., Pasbakhsh P., Fauzi M. N. A., Abu Bakar A.: Morphological, thermal and tensile properties of halloysite nanotubes filled ethylene propylene diene monomer (EPDM) nanocomposites. Polymer Testing, 27, 841-850 (2008).

DOI: $10.1016 /$ j.polymertesting.2008.06.007

[26] Hedicke-Höchstötter K., Lim G. T., Altstädt V.: Novel polyamide nanocomposites based on silicate nanotubes of the mineral halloysite. Composites Science and Technology, 69, 330-334 (2009).

DOI: 10.1016/j.compscitech.2008.10.011

[27] Du M., Guo B., Lei Y., Liu M., Jia D.: Carboxylated butadiene-styrene rubber/halloysite nanotube nanocomposites: Interfacial interaction and performance. Polymer, 49, 4871-4876 (2008).

DOI: $10.1016 /$ j.polymer.2008.08.042

[28] Ning N-Y., Yin Q-J., Luo F., Zhang Q., Du R., Fu Q.: Crystallization behavior and mechanical properties of polypropylene/halloysite composites. Polymer, 48, 7374-7384 (2007).

DOI: $10.1016 /$ j.polymer.2007.10.005

[29] Du M., Guo B., Jia D.: Thermal stability and flame retardant effects of halloysite nanotubes on poly(propylene). European Polymer Journal, 42, 1362-1369 (2006).

DOI: $10.1016 /$ j.eurpolymj.2005.12.006

[30] Liu M., Guo B., Du M., Chen F., Jia D.: Halloysite nanotubes as a novel $\beta$-nucleating agent for isotactic polypropylene. Polymer, 50, 3022-3030 (2009).

DOI: $10.1016 /$ j.polymer.2009.04.052
[31] Liu M., Guo B., Lei Y., Du M., Jia D.: Benzothiazole sulfide compatibilized polypropylene/halloysite nanotubes composites. Applied Surface Science, 255, 4961-4969 (2009).

DOI: $10.1016 /$ j.apsusc.2008.12.044

[32] Du M., Guo B., Lei Y., Jia D.: Thermal decomposition and oxidation ageing behaviour of polypropylene/halloysite nanotube nanocomposites. Polymers and Polymer Composites, 15, 321-328 (2007).

[33] Du M., Guo B., Jia D.: Newly emerging applications of halloysite nanotubes: A review. Polymer International, 59, 574-582 (2010). DOI: $10.1002 /$ pi.2754

[34] Liu M. X., Guo B. C., Du M. L, Cai X. J., Jia D. M.: Properties of halloysite nanotube-epoxy resin hybrids and the interfacial reactions in the systems. Nanotechnology, 18, 455703 (2007). DOI: $10.1088 / 0957-4484 / 18 / 45 / 455703$

[35] Vergaro V., Abdullayev E., Lvov Y. M., Zeitoun A., Cingolani R., Rinaldi R., Leporatti St.: Cytocompatibility and uptake of halloysite clay nanotubes. Biomacromolecules, 11, 820-826 (2010).

DOI: $10.1021 / \mathrm{bm} 9014446$

[36] Grossiord N., Loos J., Regev O., Koning C. E.: Toolbox for dispersing carbon nanotubes into polymers to get conductive nanocomposites. Chemistry and Materials, 18, 1089-1099 (2006).

DOI: $10.1021 / \mathrm{cm} 051881 \mathrm{~h}$

[37] Andrews R., Jacques D., Minot M., Rantell T.: Fabrication of carbon multiwall nanotube/polymer composites by shear mixing. Macromolecular Materials and Engineering, 287, 395-403 (2002).

DOI: $10.1002 / 1439-2054(20020601) 287: 6<395:: A I D-$ MAME395>3.0.CO;2-S

[38] Jang G-S., Cho W-J., Ha C-S.: Crystallization behavior of polypropylene with or without sodium benzoate as a nucleating agent. Journal of Polymer Science Part B: Polymer Physics, 39, 1001-1016 (2001).

DOI: $10.1002 /$ polb.1077

[39] Luyt A. S., Dramićanin M. D., Antić Ž., Djoković V.: Morphology, mechanical and thermal properties of composites of polypropylene and nanostructured wollastonite filler. Polymer Testing, 28, 348-356 (2009). DOI: $10.1016 /$ j.polymertesting.2009.01.010

[40] Wang L., Sheng J.: Preparation and properties of polypropylene/org-attapulgite nanocomposites. Polymer, 46, 6243-6249 (2005). DOI: $10.1016 /$ j.polymer.2005.05.067

[41] Du M., Gio B., Wan J., Zou Q., Jia D.: Effects of halloysites nanotubes on kinetics and activation energy of non isothermal crystallization of polypropylene. Journal of Polymer Research, 17, 109-118 (2010). DOI: $10.1007 / \mathrm{s} 10965-009-9296-5$ 
[42] Logakis E., Pollatos E., Pandis Ch., Peoglos V., Zuburtikudis I., Delides C. G., Vatalis A., Gjoka M., Syskakis E., Viras K., Pissis P.: Structure-property relationships in isotactic polypropylene/multi-walled carbon nanotubes nanocomposites. Composites Science and Technology, 70, 328-335 (2010). DOI: $10.1016 /$ j.compscitech.2009.10.023

[43] Krump H., Luyt A. S., Hudec I.: Effect of different modified clays on the thermal and physical properties of polypropylene-montmorillonite nanocomposites. Materials Letters, 60, 2877-2880 (2006).

DOI: $10.1016 /$ j.matlet.2006.02.006

[44] Zhang Y-Q., Lee J-H.,. Rhee J. M., Rhee K. Y.: Polypropylene-clay nanocomposites prepared by in situ grafting-intercalating in melt. Composites Science and Technology, 64, 1383-1389 (2004).

DOI: 10.1016/j.compscitech.2003.10.014

[45] Pasbakhsh P., Ismail H., Fauzi M. N. A., Abu Bakar A.: EPDM/modified halloysite nanocomposites. Applied Clay Science, 48, 405-413 (2010).

DOI: 10.1016/j.clay.2010.01.015
[46] Liu M., Guo B., Du M., Lei Y., Jia D.: Natural inorganic nanotubes reinforced epoxy resin nanocomposites. Journal of Polymer Research, 15, 205-212 (2008).

DOI: $10.1007 / \mathrm{s} 10965-007-9160-4$

[47] Ajayan P. M., Schadler L. S., Giannaris C., Rubio A.: Single-walled carbon nanotube-polymer composites: Strength and weakness. Advanced Materials, 12, 750-753 (2000).

DOI: 10.1002/(SICI)1521-4095(200005)12:10<750:: AID-ADMA750>3.0.CO;2-6

[48] Rothe B.: Influence of clay addition and processing variables on the properties of injection-moulded thermoplastic nanocomposites (in French). Master Thesis, École des Mines de Douai, France (2005).

[49] Fourdrin S., Soulestin J., Lafranche E., Lacrampe MF., Krawczak P.: Dimensional accuracy and stability of polypropylene-clay nanocomposites injectionmouldings. in 'PPS-23, The Polymer Processing Society $23^{\text {rd }}$ Annual Meeting, Salvador, Brasil' CD-ROM P03-040 (2007). 